\title{
Structural and textural features of bentonite modified with mixed cationic and nonionic surfactants
}

\author{
M. ANDRUNIK ${ }^{1 *}$ AND T. BAJDA ${ }^{1}$
}

${ }^{1}$ AGH University of Science and Technology, Faculty of Geology, Geophysics and Environmental Protection, al. Mickiewicza 30, 30-059 Krakow, Poland

(*correspondence: magtuch@agh.edu.pl)

The objective was to improve the understanding of mixed cationic-nonionic surfactant behavior on clay mineral for its possible use in remediation technologies of soil and groundwater contaminated by toxic organic compounds.

Modification of bentonite was a two-step experiment. First, the modification of bentonite with cationic surfactant (HDTMA-Br) was conducted. Then, the prepared material was modified using a nonionic surfactant (Triton X-100).

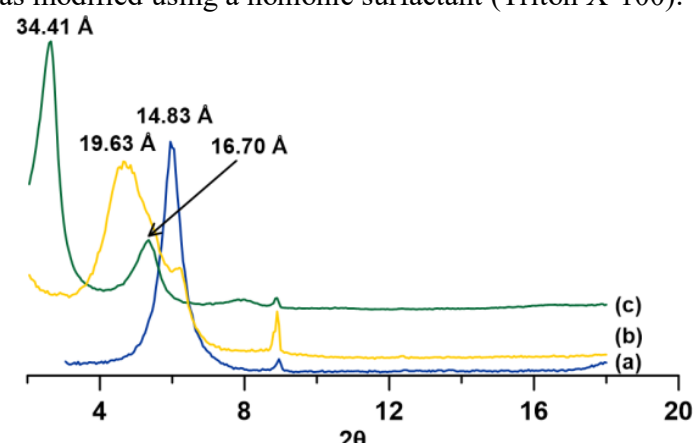

Figure 1: X-ray diffraction patterns of: (a) natural bentonite; (b) bentonite modified with HDTMA only; (c) bentonite modified with HDTMA and TX100.

XRD results showed that the main peak (001) from montmorillonite was observed to shift towards higher interlayer distances in case of modification with HDTMA. Further modification of HDTMA-bentonite with TX100 caused the formation of a new, strong peak at $34.41 \AA$ and $37.9 \AA$ (Fig. 1). The FTIR spectrum of HDTMA-modified bentonite shows bands originated from surfactant molecules. Modification with TX100 is also confirmed by new bands from $\mathrm{C}-\mathrm{C}$ bonds of phenyl rings. The specific surface area of BET of organo-bentonites decreased significantly compared to natural bentonite. The modification also affected the total pore volume; however, the proportion of individual pore classes was maintained.

This research was financed by the Foundation for Polish Science (FNP), Poland, Grant No. TEAM-NETPOIR.04.04.00-00-14E6/18-00. 